Research Article

\title{
A New Hollow-Fiber Adsorbent Material for Removing Arsenic from Groundwater
}

\author{
Sang Hyun Lee and Sung Su Kim \\ Department of Environmental Energy Engineering, Kyonggi University, 16227 Suwon, Republic of Korea \\ Correspondence should be addressed to Sung Su Kim; sskim@kyonggi.ac.kr
}

Received 10 January 2019; Accepted 22 April 2019; Published 13 May 2019

Academic Editor: Darren Sun

Copyright () 2019 Sang Hyun Lee and Sung Su Kim. This is an open access article distributed under the Creative Commons Attribution License, which permits unrestricted use, distribution, and reproduction in any medium, provided the original work is properly cited.

To optimize the arsenic-adsorption efficiency and the mechanical strength of a hollow-fiber-type adsorbent, the optimal condition of polymeric solution was determined as $32 \mathrm{wt} . \% \mathrm{TiO}_{2}$ and $17 \mathrm{wt} . \%$ polymer. A micropore-sponge form was developed at the slurry-extrusion speed of $2.500 \mathrm{ml} / \mathrm{min}$ and the internal coagulant-solution-extrusion speed of $1.250 \mathrm{ml} / \mathrm{min}$, and the arsenicadsorption efficiency improved. Given the result under conditions in natural groundwater containing various ions, the hollowfiber-type adsorbent can be applied to real groundwater purification processes.

\section{Introduction}

Arsenic-contaminated groundwater is discovered continuously around the world. It has spread across Asia, including West Bengal, Taiwan, India, Bangladesh, and China, as well as throughout North America and South America, including the United States and Mexico, and also to European nations such as Germany. Arsenic has strong human toxicity, and it causes serious worldwide health problems, including acute symptoms such as skin diseases and neurotoxicity as well as chronic illnesses such as cancers of the lung, bladder, and skin [1].

Various methods and technologies have been reported for removing arsenic from drinking water including coagulationflocculation [2, 3], oxidation [4, 5], ion exchange [6], adsorption [7-9], and membrane processes [10-12]. Investigators have indicated that adsorption is the most promising technology because of advantages including high removal efficiency, easy operation, and cost-effectiveness [13-16].

Arsenic adsorption is a processing technology that removes the dissolved substances from drinking water; specifically, the toxin adheres to the surface of the adsorbent, and the adsorbent determines its efficiency. Researchers have thus been investigating developing diverse adsorbents with improved efficiency including currently commercialized adsorbents, specifically, diverse metallic (hydr)oxides, such as aluminum oxide [17-19], iron (hydr)oxide [20-23], titanium dioxide [24, 25], zinc oxide [26], copper oxide [27], cerium hydr(oxide) [28], and zirconium oxide [29].

$\mathrm{TiO}_{2}$ is being used widely as a nonorganic chemical for diverse materials such as synthetic textiles, paints, rubber, paper, and plastics, and researchers are studying using the chemical for purposes such as separating pollutants in gases and filtering groundwater. The authors have recently reported rapid increases in research on the $\mathrm{TiO}_{2}$-based adsorption of arsenic [30] on forms such as $\mathrm{TiO}_{2}$ nanoparticles $[25,31]$, titanate nanotubes [32], hydrous $\mathrm{TiO}_{2}$ [33], granular $\mathrm{TiO}_{2}[34,35]$, and $\mathrm{TiO}_{2}$-impregnated chitosan beads [36].

In this study, we produced a $\mathrm{TiO}_{2}$-based polymeric hollow fiber using nonsolvent-induced phase separation (NIPS) and cut it small for use as an arsenic adsorbent. NIPS is a phase-transition phenomenon in which a polymer and a solvent are mixed uniformly to form a polymer solution; when the solvent that is contained in the polymer solution comes into contact with the nonsolvent (coagulant), the solvent in the polymer solution is exchanged with the nonsolvent via diffusion and convection, thereby separating the solvent into solid and liquid phases [37, 38]. The polymeric solution, which is a raw hollow-fiber material, is extruded through the mold and passes through the NIPS 
reaction twice, to react once with the internal and external coagulants. Through this process, the sponge (micro-) pore and the finger-form (macro- or meso-) pore are formed in the hollow fiber [39], and these greatly affect the diverse physiochemical characteristics of the fiber such as the nonsuperficial and flux characteristics. Hollow fiber can be tailored depending on the need by adjusting these characteristics, and therefore, research is important on developing hollow fiber for diverse uses such as in membranes for water treatment and gas separation $[37,38]$. However, no researcher has yet reported on producing and applying a polymer-based hollow fiber as an adsorbent for arsenic removal. Thus, for this study, we conducted process optimization to produce a hollow fiber for arsenic adsorption by examining how these numerous pores remove arsenic across the wide specific surface areas and the cross sections of hollow fibers.

\section{Materials and Methods}

2.1. Preparation of Titanium Hollow-Fiber Adsorbents. We prepared the hollow-fiber adsorbent by NIPS using polysulfone from Solvay Co. (Brussels, Belgium) as the polymer and 1-methyl-2-pyrrolidone from Sigma-Aldrich (St. Louis, MO, USA) as the solvent. We used $\mathrm{TiO}_{2}$ from Cristal Co. (Jeddah, Saudi Arabia) and polyvinylpyrrolidone (PVP) from Sigma-Aldrich as the pore-formation additive. First, the dried polysulfone was mixed with the $N$-methyl-2pyrrolidone (NMP) solvent, and after the $\mathrm{TiO}_{2}$ and the PVP were added, the polymeric solution was produced after $24 \mathrm{hr}$ stirring. Then, the produced solution was degassed in a vacuum desiccator for $5 \mathrm{hr}$, placed in a syringe pump, connected to a spinneret, and finally extruded with an internal coagulant (Figure 1). The produced hollow fiber was subsequently maintained in an external coagulant for $6 \mathrm{hr}$ and then cut to a length of $0.5 \mathrm{~cm}$, kept in an oven at $105^{\circ} \mathrm{C}$ to eliminate the remaining moisture, and cooled in a desiccator.

\subsection{Evaluating the Arsenic-Adsorption Efficiency in a Batch} Reactor. We evaluated the arsenic-adsorption efficiency: the solution was first filtered. After that, we placed the adsorbent in the batch reactor; this was followed by arsenic adsorption at $20^{\circ} \mathrm{C}$ agitation temperature, agitation speed of $60 \mathrm{rpm}$, and less than $50 \mathrm{hr}$ of agitation time; then, we measured the arsenic concentration. We produced the solution used in the arsenic-adsorption experiment using $99.0 \%$ sodium arsenite $\left(\mathrm{NaAsO}_{2}\right)$ obtained from Kanto Chemical (Tokyo, Japan) and conducted the experiment by setting the initial arsenic concentration to $0.2 \mathrm{mg} / \mathrm{L}$ in consideration of the actual concentrations in discharged groundwater.

We analyzed the arsenic using silver- (Ag-) diethyldithiocarbamate (DDTC), a colorimetric method. After we injected 36\% hydrogen chloride (Sigma-Aldrich), we measured the potassium iodide and tin chloride concentrations in the sample; then, we injected granulated zinc (SigmaAldrich) that was captured from the Ag-DDTC solution into the sample to convert the arsenic into arsine $\left(\mathrm{AsH}_{3}\right)$ gas. The color of the solution changed according to the amount of $\mathrm{AsH}_{3}$ that had been adsorbed in the wavelength of $520 \mathrm{~nm}$.

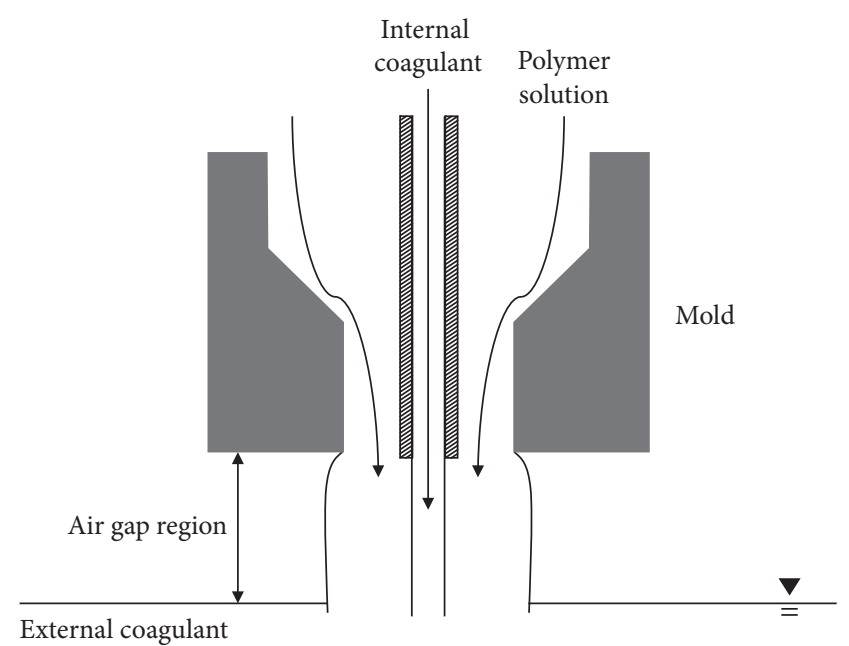

Figure 1: Schematic diagram of preparing hollow-fiber adsorbents by nonsolvent-induced phase separation.

2.3. Characterizing the Materials. To observe the surface of the adsorbent, we analyzed the samples fixed with the carbon tape using the Hitachi S-4800 (Hitachi Co., Japan) for scanning electron microscopy (SEM). To analyze the specific surface area and the pore size of the adsorbent, we used the Micromeritics ASAP 2010C analyzer (Micromeritics Co., Norcross, GA, USA) and obtained the specific surface area using the BET (Brunauer-Emmett-Teller) formula. We calculated the pore-size distribution according to the $\mathrm{BJH}$ (Barrett-Joyer-Hanlenda) method, which is used for calculating micropore size when the average liquid-meniscus radius according to the Kelvin formula and the thickness of the relative-pressure adsorption layer are known. After the gas was eliminated at room temperature $\left(20^{\circ} \mathrm{C}\right)$ for $2 \mathrm{hr}$ to prevent any high-temperature changes, we analyzed each sample, measuring material tensile strength using a universal testing machine. We applied weight continuously to calculate the tensile strength through the length to the sample rupture point.

\subsection{Evaluating Arsenic-Adsorption Efficiency in a} Continuous-Flow System Reactor. To evaluate the applicability of the continuous-flow process regarding the prepared adsorbent, we performed the experiment using an empty bed contact time (EBCT) column. We used the columnadsorption experiment to evaluate the breakthrough time and the pollutant-removal efficiency of the fixed-bed column, and for this study, set the point at which the discharge water exceeded the drinking-water standard of $0.01 \mathrm{mg} / \mathrm{L}$ as the reference breakthrough point. The column was made using an acrylic with the following specifications: $8 \mathrm{~mm}$ thick, $500 \mathrm{~mm}$ long, $20 \mathrm{~mm}$ horizontal width, and $20 \mathrm{~mm}$ vertical width. The column was designed to facilitate inflow and outflow provided by two $10 \mathrm{~mm}$-diameter installations; one of these was located at the top of the column and the other at the bottom. The device was composed of a source water tank, a volume pump, and a column-connection tube. Water flowed in as the up flow through the controlled 
volume pump, and we measured the arsenic concentrations $24 \mathrm{hr}$ after the EBCT was set differently according to the operating condition.

\section{Results and Discussion}

3.1. Optimizing the Hollow-Fiber Adsorbent Material. The diverse applications of $\mathrm{TiO}_{2}$ include paints, photocatalysts, and catalyst supports. To evaluate its applicability as a source material of hollow-fiber adsorbent, we evaluated the adsorption efficiency of $\mathrm{TiO}_{2}$ powder, as shown in Figure 2 and Table 1.

The Langmuir isotherm is expressed by the following equation:

$$
q_{\mathrm{e}}=\frac{q_{\mathrm{m}} b C_{\mathrm{e}}}{\left(1+b C_{\mathrm{e}}\right)},
$$

where $q_{\mathrm{e}}(\mu \mathrm{g} / \mathrm{g})=$ amount of adsorbed adsorbate per unit mass of the adsorbent, $C_{\mathrm{e}}(\mu \mathrm{g} / \mathrm{L})=$ unadsorbed adsorbent concentration in the solution at the equilibrium condition, $q_{\mathrm{m}}(\mu \mathrm{g} / \mathrm{g})=$ maximum amount of adsorbate that was adsorbed per unit mass of the adsorbent to form a complete monolayer on the surface, and $b(\mathrm{~L} / \mu \mathrm{g})=$ Langmuir constant.

Both the monolayer and multilayer adsorption processes can be studied using the following Freundlich adsorption isotherm, as it considers the adsorption of an adsorbate onto a heterogeneous adsorbent surface:

$$
q_{\mathrm{e}}=K_{\mathrm{f}} C_{\mathrm{e}}^{1 / n}
$$

where $K_{\mathrm{f}}$ and $1 / n$ represent the number of adsorption sites and the adsorption strength, respectively; $q_{\mathrm{m}}$ is the maximum adsorption capacity of the adsorbent; and $b$ is the Langmuir coefficient, which is between the adsorbent and the adsorbate. On isothermal adsorption analysis of the $\mathrm{TiO}_{2}$ powder sample, both $K_{\mathrm{f}}$ and $q_{\mathrm{m}}$ were excellent.

For the hollow-fiber material, factors that affect pore formation are the solvent-dissolution rate, dispersant, metal oxide powder, and binder contents. Therefore, to determine the optimal slurry ratio, we measured the arsenic-adsorption efficiencies of the hollow-fiber adsorbents with different source contents (Table 2 and Figure 3).

The most important factor in determining the arsenicadsorption efficiency of a hollow-fiber adsorbent is the content of the metal oxide, which is $\mathrm{TiO}_{2}$ here. As shown in Table 2, we produced the adsorbent by reducing the amount of NMP proportional to the increase of the $\mathrm{TiO}_{2}$ content under the following conditions: $\left(\mathrm{THF}_{\mathrm{a}} \sim \mathrm{THF}_{\mathrm{c}}\right)$. Furthermore, we reduced the polymer amount in the adsorbent of $\mathrm{THF}_{\mathrm{d}}$ and $\mathrm{THF}_{\mathrm{e}}$ conditions. The critical titanium content for optimal performance was $30 \%$.

Because evaluating efficiency under specific conditions can distort the specific activity of the material, we performed isothermal adsorption tests (Freundlich and Langmuir) to verify the exact efficiency and mechanism; the results, shown in Tables 3 and 4, agreed with the findings in Figure 2.

The hollow fiber has a large pore in the form of a finger and a sponge-pore form that contains numerous micropores.
According to the results in Table 5, $\mathrm{THF}_{\mathrm{d}}$ and $\mathrm{THF}_{\mathrm{e}}$ showed larger specific surface areas than the other fibers, indicating more involved micropores. The results further suggest that the sponge-like pore is more important than the finger-like structure in hollow-fiber adsorption.

In the real-world application of the adsorbent, exposing the adsorbent to high pressure, such as injecting a large amount of adsorbent or backwash, occurred frequently. Therefore, the adsorption efficiency and the mechanical strength are both very important. In terms of the Fe oxidebased commercial adsorbents in the actual process, the mechanical strength was relatively weak, and the coloring phenomenon that affects residential drinking water occurred during the backwash process. Therefore, it was necessary to verify the correlation between the mixing ratio and the mechanical strength and to determine the optimal condition by measuring the tensile strength of the hollow-fiber adsorbent that was produced by each mixing ratio (Table 6).

We confirmed that both $\mathrm{Ti}$ and polymer content can affect tensile strength. The tensile strength of silicone rubber, a ubiquitous material in daily life, ranges from 5.08 to 7.17 MPa [40], and the tensile strength of medium-strength concrete is $1.40-4.00 \mathrm{MPa}$ [41]. Considering these facts together with the results of the present study, the tensile strength of the $\mathrm{THF}_{\mathrm{e}}$ adsorbent with the lowest tensile strength is the same as that of concrete, and this tensile strength is sufficient for an adsorbent.

As presented in the introduction, the hollow-fiber adsorbent consists of far more micropores than the diverse adsorbents that are currently being used, and the micropores can be divided into finger-like and sponge-like structures according to the shape. In manufacturing hollow fibers using the NIPS method, the coagulation speed of the polymer is the important factor in determining the hollow-fiber pore structure [42], and the factors that influence the polymer's coagulation speed are the slurry-extrusion speed and the extrusion speed of the internal-coagulant solution. Our analyses thus showed differences in the pore structures according to different variables that affect pore formation, and we also investigated correlations between the pore structure and the arsenic-adsorption efficiency. Chung et al. [43] reported that increasing the polymer-extrusion speed induces the polymer-chain orientation and promotes a more densely packed formation regarding the oriented polymer chain, eventually creating a dense skin layer. Therefore, we expected increased formation of the sponge-like pore structure with increased polymer-solution extrusion speed, with decreased formation of the large-diameter finger-like pores. In this study, we produced the hollow-fiber adsorbent by adjusting its extrusion speed, analyzed the pore structure with SEM, and measured the arsenic-adsorption efficiency of the adsorbent to determine the correlation of the pore structure to the adsorption efficiency. The microporestructure observation results based on the slurry-extrusion speed are illustrated in Figure 4.

In the SEM analysis results, finger-like pores are clearly evident in the hollow fiber from the slurry extruded at the low speed of $0.312 \mathrm{ml} / \mathrm{min}$; it is also clear that, in contrast, increasing the extrusion speed to $1.250 \mathrm{ml} / \mathrm{min}$ and then 

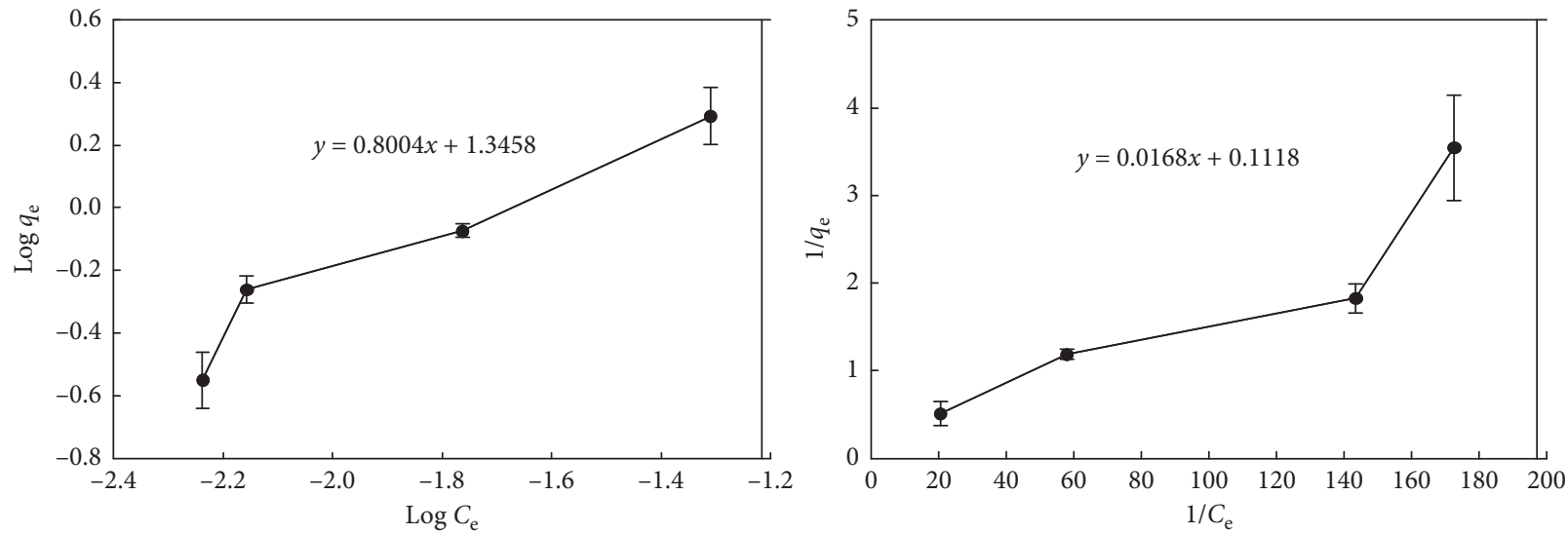

FIGURE 2: Arsenic adsorption efficiencies of commercial titanium powders (initial As concentration: $0.2 \mathrm{mg} / \mathrm{L}$; quantity of adsorbents: $0.01 \mathrm{~g})$.

Table 1: Freundlich and Langmuir isotherm analysis of $\mathrm{TiO}_{2}$ powders with different compositions.

\begin{tabular}{lc}
\hline Constants of Freundlich and Langmuir isotherm & Value \\
\hline $1 / n$ & 0.801 \\
$K_{\mathrm{f}}$ & 22.170 \\
$R^{2}$ (Freundlich) & 0.932 \\
$q_{\mathrm{m}}$ & 8.945 \\
$b$ & 6.654 \\
$R^{2}$ (Langmuir) & 0.845 \\
\hline
\end{tabular}

TABle 2: Contents and specific surface areas of hollow-fiber adsorbents with different compositions.

\begin{tabular}{lccccc}
\hline $\begin{array}{l}\text { Hollow-fiber } \\
\text { adsorbents }\end{array}$ & $\begin{array}{c}\text { Content of titanium } \\
(\text { wt. } \%)\end{array}$ & $\begin{array}{c}\text { Content of NMP } \\
(\text { wt.\%) }\end{array}$ & $\begin{array}{c}\text { Content of polymer } \\
\text { (wt.\%) }\end{array}$ & $\begin{array}{c}\text { Content of PVP } \\
(\text { wt.\%) }\end{array}$ & $\begin{array}{c}\text { Specific surface area } \\
\left(\mathrm{m}^{2} / \mathrm{g}\right)\end{array}$ \\
\hline $\mathrm{THF}_{\mathrm{a}}$ & 20 & 58 & 21 & 1 & 49 \\
$\mathrm{THF}_{\mathrm{b}}$ & 23 & 55 & 21 & 1 & 51 \\
$\mathrm{THF}_{\mathrm{c}}$ & 28 & 50 & 21 & 1 & 63 \\
$\mathrm{THF}_{\mathrm{d}}$ & 32 & 50 & 17 & 1 & 114 \\
$\mathrm{THF}_{\mathrm{e}}$ & 34 & 50 & 15 & 1 & 113 \\
\hline
\end{tabular}

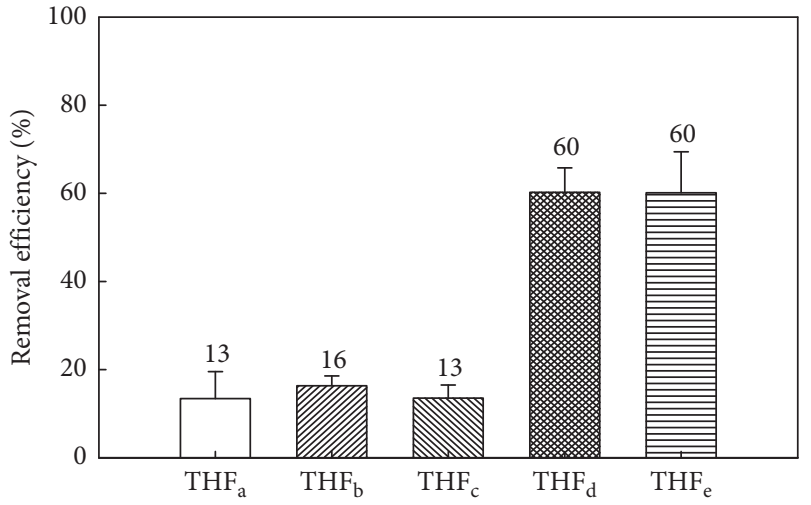

Figure 3: Arsenic adsorptive efficiencies of titanium hollow-fiber adsorbents with different compositions (initial As concentration: $0.2 \mathrm{mg} / \mathrm{L}$; quantity of adsorbents: $0.1 \mathrm{~g}$ ).
TABLE 3: Freundlich isotherm analysis of hollow-fiber adsorbents with different compositions.

\begin{tabular}{lccc}
\hline Hollow-fiber adsorbents & $K_{\mathrm{f}}$ & $1 / n$ & $R^{2}$ \\
\hline $\mathrm{THF}_{\mathrm{a}}$ & 1.681 & 0.975 & 0.853 \\
$\mathrm{THF}_{\mathrm{b}}$ & 1.406 & 0.962 & 0.995 \\
$\mathrm{THF}_{\mathrm{c}}$ & 1.724 & 0.959 & 0.901 \\
$\mathrm{THF}_{\mathrm{d}}$ & 2.673 & 0.946 & 0.941 \\
$\mathrm{THF}_{\mathrm{e}}$ & 2.647 & 0.941 & 0.918 \\
\hline
\end{tabular}

$2.500 \mathrm{ml} / \mathrm{min}$ increased the development of the sponge-like pores, and as these developed, the formation of the fingerlike sponge was relatively restricted. Based on these results, we verified a correlation between hollow-fiber adsorbent pore structure and arsenic-adsorption efficiency (Figure 5).

In the arsenic-adsorption evaluation results of our above analyses, the hollow-fiber arsenic adsorbents extruded from 
TABLE 4: Langmuir isotherm analysis of hollow-fiber adsorbents with different compositions.

\begin{tabular}{lccc}
\hline Hollow-fiber adsorbents & $q_{\mathrm{m}}$ & $b$ & $R^{2}$ \\
\hline $\mathrm{THF}_{\mathrm{a}}$ & 2.915 & 0.652 & 0.859 \\
$\mathrm{THF}_{\mathrm{b}}$ & 2.849 & 1.158 & 0.998 \\
$\mathrm{THF}_{\mathrm{c}}$ & 2.944 & 0.951 & 0.926 \\
$\mathrm{THF}_{\mathrm{d}}$ & 3.448 & 0.968 & 0.938 \\
$\mathrm{THF}_{\mathrm{e}}$ & 3.418 & 0.975 & 0.918 \\
\hline
\end{tabular}

TABLE 5: BET analysis of hollow-fiber adsorbents with different compositions.

\begin{tabular}{lcc}
\hline Adsorbents & Surface area $\left(\mathrm{m}^{2} / \mathrm{g}\right)$ & Average pore diameter $(\mathrm{nm})$ \\
\hline $\mathrm{THF}_{\mathrm{a}}$ & 49 & 9.2 \\
$\mathrm{THF}_{\mathrm{b}}$ & 58 & 8.1 \\
$\mathrm{THF}_{\mathrm{c}}$ & 63 & 7.9 \\
$\mathrm{THF}_{\mathrm{d}}$ & 114 & 4.0 \\
$\mathrm{THF}_{\mathrm{e}}$ & 113 & 6.8 \\
\hline
\end{tabular}

TABLE 6: Tensile stress analysis of hollow-fiber adsorbents with different compositions.

\begin{tabular}{lc}
\hline Hollow-fiber adsorbents & Tensile stress (MPa) \\
\hline $\mathrm{THF}_{\mathrm{a}}$ & 1.98 \\
$\mathrm{THF}_{\mathrm{b}}$ & 2.86 \\
$\mathrm{THF}_{\mathrm{c}}$ & 4.10 \\
$\mathrm{THF}_{\mathrm{d}}$ & 1.44 \\
$\mathrm{THF}_{\mathrm{e}}$ & 1.40 \\
\hline
\end{tabular}

slurry at extrusion speeds of $1.250 \mathrm{ml} / \mathrm{min}$ and $2.500 \mathrm{ml} / \mathrm{min}$, with increased development of the sponge-like pores, showed excellent efficiency, and we concluded that this result was caused by the increased specific surface area from the considerable quantity of sponge-like pores.

Reuvers and Smolders [44] reported that, in general, if the exchange velocity of the hollow-fiber slurry and the nonsolvent is rapid, the large-diameter finger-like pores form, whereas a slow exchange velocity results in the formation of the sponge-like pores. The following two factors can adjust the exchange velocity of the slurry and the nonsolvent: the slurry extrusion speed and the flow rate of the internal-coagulant solution. We confirmed earlier in this paper that greater slurry-extrusion speed increases spongelike-pore development, and based on these findings, we evaluated the pore-structure change by varying the internalcoagulant flow rate; the results are shown in Figure 6.

For the internal-coagulant solution, we produced the distilled water using a Puris water purification system (Miraest Co. Ltd., Gyeonggi-do, South Korea), and we produced the hollow-fiber adsorbent by adjusting the extrusion speed from 1.250 to $5.000 \mathrm{ml} / \mathrm{min}$. We confirmed that the faster the flux of the internal-coagulant solution, the wider the distribution of the finger-like pores, whereas the slower the flux, the wider the distribution of the sponge-like pores. Decreasing the flux of the internal-coagulant solution decreased the exchange speed of the slurry and the nonsolvent, which means that the dissolution speed of the NMP in the internal coagulant decreased significantly. We determined that a considerable number of sponge-like pores were generated, which was confirmed by literature results [45].

As previously discussed, the slurry-mixing ratio and the extrusion speed contributed greatly to the change of the pore structure, and the arsenic-adsorption efficiency varied greatly according to the pore-structure change. The extrusion speed of the internal-coagulant solution affected the pore-structure change, leading to the conclusion that this process can change the efficiency; based on that conclusion, we measured the arsenic-adsorption efficiency of the adsorbents that were produced under each condition; these results are shown in Figure 7.

These evaluation results show that the adsorption efficiency was highest for the hollow-fiber adsorbent that was produced at an internal-coagulant solution extrusion speed of $1.250 \mathrm{ml} / \mathrm{min}$. We also determined that increasing the extrusion speed decreased the adsorption efficiency. This result shows that arsenic-adsorption efficiency improves with more sponge-like pores, the micropores, in the fiber.

\subsection{Evaluating the Hollow-Fiber Adsorbent Applicability in} the Actual Process. We also tested the arsenic-adsorption efficiency of hollow-fiber adsorbents in groundwater that contained ions other than arsenic (Figure 8), primarily nitrate nitrogen, trihalomethane, hardness, free residual chlorine, and sulfate but also boron, chloroform, bromodichloromethane, chloral hydrate, dibromoacetonitrile, haloacetic acid, uranium, chemical oxygen demand, and evaporation residue. With the titanium-based hollow-fiber adsorbent, the difference in the arsenic-adsorption rate between the general synthetic wastewater and the actual groundwater was trivial. With the metaloxide-based granular type of commercial adsorbent, however, the adsorption efficiency was greatly reduced.

Based on actual arsenic adsorption, we evaluated the adsorbent efficiency of the continuous-flow system we had designed at the lab scale for this study. We verified the efficiency by varying the setting of the EBCT, the influent per mass of the injected adsorbent $[34,45]$; the corresponding results are shown in Figure 9.

In the experimental results in hollow-fiber-adsorbent mode 1 (EBCT: $3 \mathrm{~min}$ ), the permeation results were converted into a concentration that was the same as the injected concentration within 11 days, and in mode 2 (EBCT: $5 \mathrm{~min}$ ), the same concentration was reached at the breakthrough point. In mode 4 (EBCT: $25 \mathrm{~min}$ ), the concentration of $0.01 \mathrm{mg} / \mathrm{L}$, the drinking-water standard, was achieved within 35 days. The results of this study verified the applicability of the hollow-fiber adsorbent in the continuous-flow system, and they show that the hollow fiber can be applied when EBCT varies according to the influent condition.

\section{Conclusions}

In this study, we produced titanium-based polymeric hollow-fiber arsenic adsorbents with diverse pore structures and excellent specific surface area. To maximize the arsenic- 


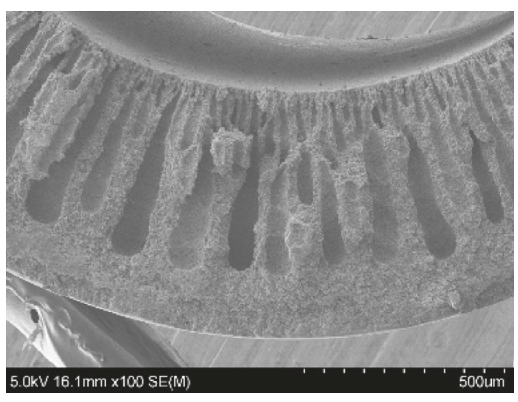

(a)

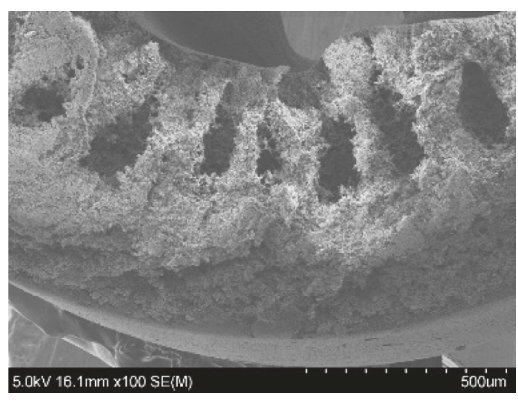

(b)

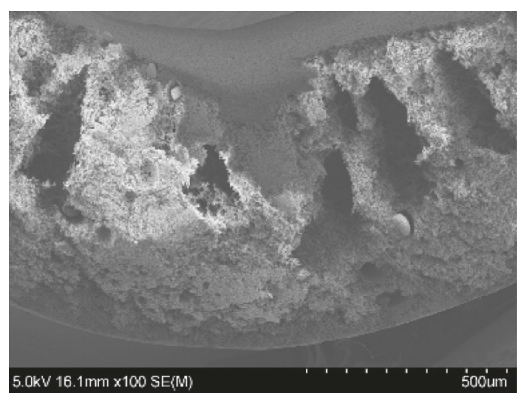

(c)

FIGURE 4: SEM images of hollow-fiber adsorbents manufactured under different slurry velocity conditions: (a) $0.312 \mathrm{ml} / \mathrm{min}$; (b) $1.250 \mathrm{ml} / \mathrm{min}$; (c) $2.500 \mathrm{ml} / \mathrm{min}$.

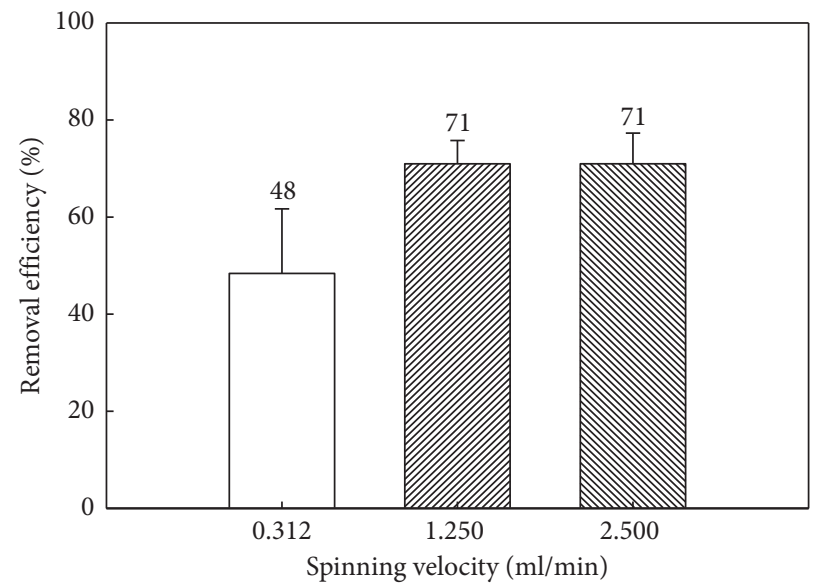

FIGURE 5: Arsenic-adsorptive efficiency of hollow-fiber adsorbents by slurry spinning velocity (initial As concentration: $0.2 \mathrm{mg} / \mathrm{L}$; quantity of adsorbents: $0.1 \mathrm{~g}$ ).

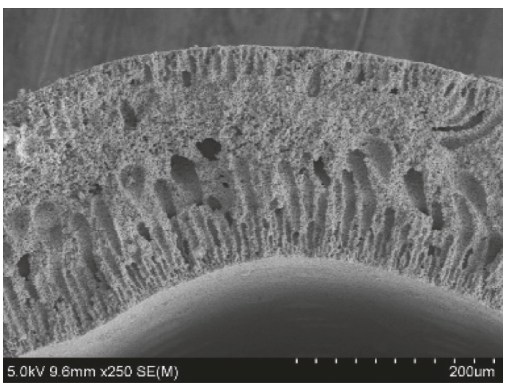

(a)

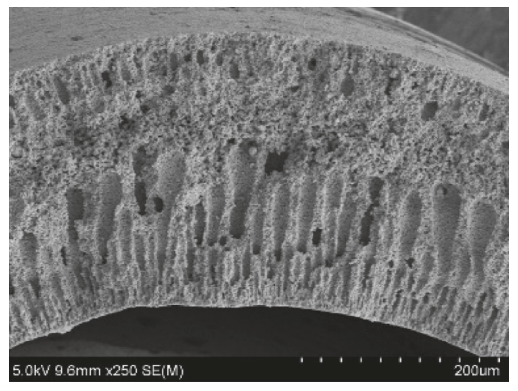

(b)

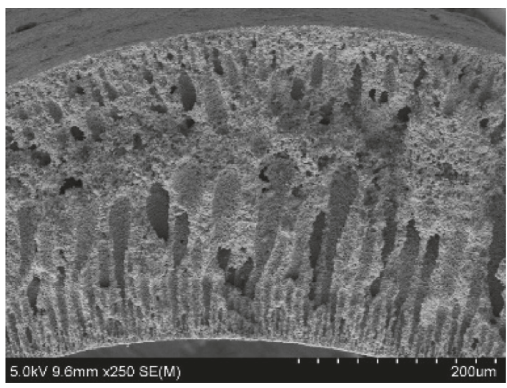

(c)

FIGURE 6: SEM images of titanium hollow-fiber adsorbents obtained at different inner-coagulating spinning velocities: (a) $1.25 \mathrm{ml} / \mathrm{min}$; (b) $2.50 \mathrm{ml} / \mathrm{min}$; (c) $5.00 \mathrm{ml} / \mathrm{min}$.

adsorption efficiency and the mechanical strength of the adsorbents, we optimized the contents of NMP, polyurethane, metal oxide $\left(\mathrm{TiO}_{2}\right)$, and PVP, the raw materials. We confirmed that the optimal raw material for determining arsenic-adsorption efficiency was $\mathrm{TiO}_{2}$ and the optimal substance for determining mechanical strength was polyurethane. Based on our findings and experimental results, the sample $\mathrm{THF}_{\mathrm{d}}$ was optimal.
We examined the adsorption efficiency and the pore structure of the samples by adjusting the extrusion speed of the internal coagulant and hollow-fiber solutions. As the polymeric solutions' extrusion speed increased and the extrusion speed of the internal coagulant solution decreased, more sponge-like, dense pores formed than finger-like pores. Additionally, arsenic-adsorption efficiency improved as the specific surface area increased. 


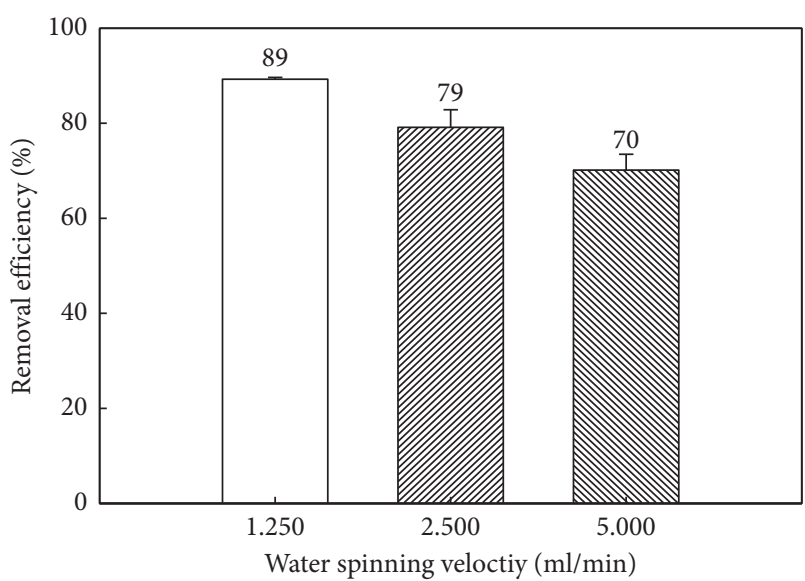

Figure 7: Arsenic removal efficiency of titanium hollow-fiber adsorbents obtained by another spinning velocity of inner coagulation (initial As concentration: $0.2 \mathrm{mg} / \mathrm{L}$; quantity of adsorbents: $0.1 \mathrm{~g}$ ).

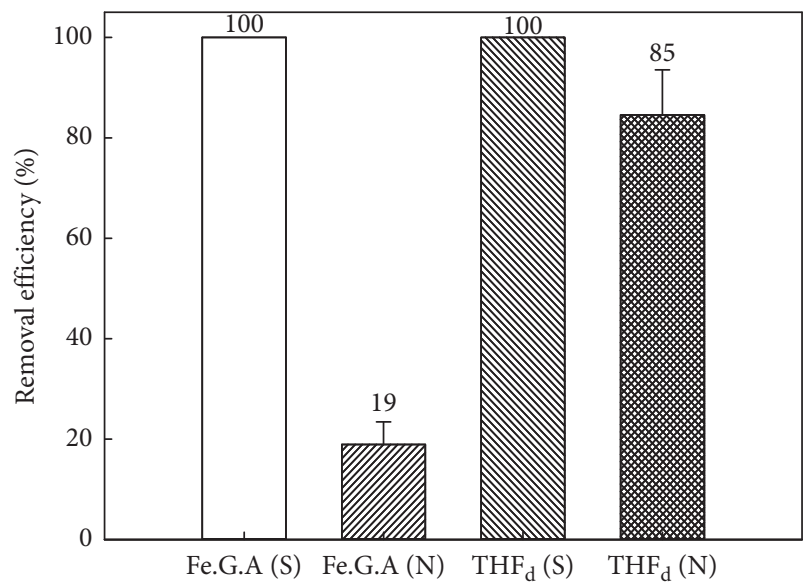

FIGURE 8: Effects of iron-based adsorbents on other ions and $\mathrm{THF}_{\mathrm{d}}$ on the As adsorption reaction (Fe.G.A: iron- (Fe-) based granular adsorbents; S: synthetic wastewater; N: natural wastewater; initial As concentration: $0.2 \mathrm{mg} / \mathrm{L}$; quantity of adsorbents: $0.1 \mathrm{~g}$ ).

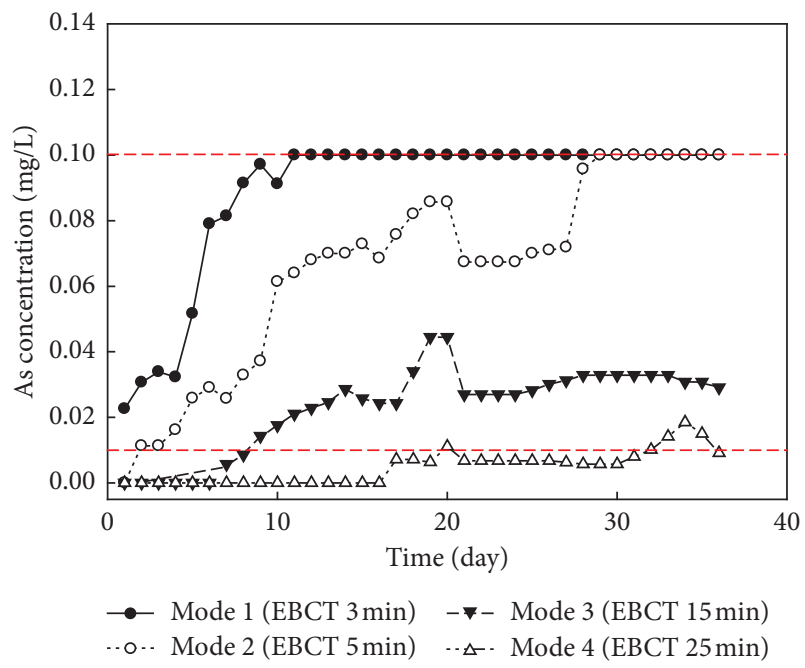

FIGURE 9: Outlet As concentration in a continuous flow system using $\mathrm{THF}_{\mathrm{d}}$ (initial As concentration: $0.1 \mathrm{mg} / \mathrm{L}$; inflow discharge: $2.9 \mathrm{~L} /$ day).
We finally evaluated the arsenic-adsorption efficiency of the hollow-fiber adsorbents we produced in actual underground groundwater with ions other than arsenic. The adsorbents produced using titanium showed excellent efficiency even in the actual groundwater, in contrast with the granular type of commercial adsorbents manufactured using metal oxides. We also verified the efficiency of the adsorbent by manufacturing a lab-scale continuous-flow system, similar to the actual process. We observed that the effluent concentration varied according to EBCT, which is the case in the actual process.

\section{Data Availability}

The data used to support the findings of this study are available from the corresponding author upon request.

\section{Conflicts of Interest}

The authors declare that there are no conflicts of interest regarding the publication of this article.

\section{Acknowledgments}

This work was supported by Kyonggi University Research Grant 2016.

\section{References}

[1] WHO and World Health Report, Health Systems: Improving Performance, World Health Organization, 2000.

[2] F. Hesami, B. Bina, A. Ebrahimi, and M. M. Amin, "Arsenic removal by coagulation using ferric chloride and chitosan from water," International Journal of Environmental Health Engineering, vol. 2, no. 1, p. 17, 2013.

[3] Y. Sun, G. Zhou, X. Xiong, X. Guan, L. Li, and H. Bao, "Enhanced arsenite removal from water by $\mathrm{Ti}\left(\mathrm{SO}_{4}\right)_{2}$ coagulation," Water Research, vol. 47, no. 13, pp. 4340-4348, 2013.

[4] C. Hu, H. Liu, G. Chen, W. A. Jefferson, and J. Qu, "As(III) oxidation by active chlorine and subsequent removal of $\mathrm{As}(\mathrm{V})$ by $\mathrm{Al}_{13}$ polymer coagulation using a novel dual function reagent," Environmental Science \& Technology, vol. 46, no. 12, pp. 6776-6782, 2012.

[5] S. Sorlini and F. Gialdini, "Conventional oxidation treatments for the removal of arsenic with chlorine dioxide, hypochlorite, potassium permanganate and monochloramine," Water Research, vol. 44, no. 19, pp. 5653-5659, 2010.

[6] M. Jang, S.-H. Min, T.-H. Kim, and J. K. Park, "Removal of arsenite and arsenate using hydrous ferric oxide incorporated into naturally occurring porous diatomite," Environmental Science \& Technology, vol. 40, no. 5, pp. 1636-1643, 2006.

[7] J. A. Wilkie and J. G. Hering, "Adsorption of arsenic onto hydrous ferric oxide: effects of adsorbate/adsorbent ratios and co-occurring solutes," Colloids and Surfaces A: Physicochemical and Engineering Aspects, vol. 107, pp. 97-110, 1996.

[8] R. Singh, S. Singh, P. Parihar, V. P. Singh, and S. M. Prasad, "Arsenic contamination, consequences and remediation techniques: a review," Ecotoxicology and Environmental Safety, vol. 112, pp. 247-270, 2015.

[9] T. R. Holm, "Effects of $\mathrm{CO}_{3}{ }^{2-} /$ bicarbonate, $\mathrm{Si}$, and $\mathrm{PO}_{4}{ }^{3-}$ on Arsenic sorption to HFO," Journal-American Water Works Association, vol. 94, no. 4, pp. 174-181, 2002. 
[10] F. Beolchini, F. Pagnanelli, I. De Michelis, and F. Veglio, "Treatment of concentrated arsenic $(\mathrm{V})$ solutions by micellar enhanced ultrafiltration with high molecular weight cut-off membrane," Journal of Hazardous Materials, vol. 148, no. 1-2, pp. 116-121, 2007.

[11] H. Gecol, E. Ergican, and A. Fuchs, "Molecular level separation of arsenic $(\mathrm{V})$ from water using cationic surfactant micelles and ultrafiltration membrane," Journal of Membrane Science, vol. 241, no. 1, pp. 105-119, 2004.

[12] A. Figoli, A. Cassano, A. Criscuoli et al., "Influence of operating parameters on the arsenic removal by nanofiltration," Water Research, vol. 44, no. 1, pp. 97-104, 2010.

[13] T. S. Singh and K. K. Pant, "Equilibrium, kinetics and thermodynamic studies for adsorption of As(III) on activated alumina," Separation and Purification Technology, vol. 36, no. 2, pp. 139-147, 2004.

[14] D. Mohan and C. U. Pittman Jr., "Arsenic removal from water/wastewater using adsorbents-a critical review," Journal of Hazardous Materials, vol. 142, no. 1-2, pp. 1-53, 2007.

[15] M. Jang, W. Chen, and F. S. Cannon, "Preloading hydrous ferric oxide into granular activated carbon for arsenic removal," Environmental Science \& Technology, vol. 42, no. 9, pp. 3369-3374, 2008.

[16] A. Anjum, P. Lokeswari, M. Kaur, and M. Datta, "Removal of As (III) from aqueous solutions using montmorillonite," Journal of Analytical Sciences, Methods and Instrumentation, vol. 1, no. 2, pp. 25-30, 2011.

[17] L. Önnby, V. Pakade, B. Mattiasson, and H. Kirsebom, "Polymer composite adsorbents using particles of molecularly imprinted polymers or aluminium oxide nanoparticles for treatment of arsenic contaminated waters," Water Research, vol. 46, no. 13, pp. 4111-4120, 2012.

[18] S. Saha and P. Sarkar, "Arsenic remediation from drinking water by synthesized nano-alumina dispersed in chitosangrafted polyacrylamide," Journal of Hazardous Materials, vol. 227-228, pp. 68-78, 2012.

[19] A. K. Darban, Y. Kianinia, and E. Taheri-Nassaj, "Synthesis of nano- alumina powder from impure kaolin and its application for arsenite removal from aqueous solutions," Journal of Environmental Health Science \& Engineering, vol. 11, no. 1, p. 19, 2013.

[20] T. M. S. Attia, X. L. Hu, and D. Q. Yin, "Synthesised magnetic nanoparticles coated zeolite (MNCZ) for the removal of arsenic (As) from aqueous solution," Journal of Experimental Nanoscience, vol. 9, no. 6, pp. 551-560, 2014.

[21] L. Feng, M. Cao, X. Ma, Y. Zhu, and C. Hu, "Superparamagnetic high-surface-area $\mathrm{Fe}_{3} \mathrm{O}_{4}$ nanoparticles as adsorbents for arsenic removal," Journal of Hazardous Materials, vol. 217-218, pp. 439-446, 2012.

[22] A. V. Vitela-Rodriguez and J. R. Rangel-Mendez, "Arsenic removal by modified activated carbons with iron hydro(oxide) nanoparticles," Journal of Environmental Management, vol. 114, pp. 225-231, 2013.

[23] T. Türk and İ. Alp, "Arsenic removal from aqueous solutions with Fe-hydrotalcite supported magnetite nanoparticle," Journal of Industrial and Engineering Chemistry, vol. 20, no. 2, pp. 732-738, 2014.

[24] Z. Wei, K. Liang, Y. Wu et al., "The effect of $\mathrm{pH}$ on the adsorption of arsenic(III) and $\operatorname{arsenic}(\mathrm{V})$ at the $\mathrm{TiO}_{2}$ anatase $\left[\begin{array}{lll}1 & 0 & 1\end{array}\right]$ surface," Journal of Colloid and Interface Science, vol. 462, pp. 252-259, 2016.

[25] D. Nabi, I. Aslam, and I. A. Qazi, "Evaluation of the adsorption potential of titanium dioxide nanoparticles for arsenic removal," Journal of Environmental Sciences, vol. 21, no. 3, pp. 402-408, 2009.

[26] N. Singh, S. P. Singh, V. Gupta et al., "A process for the selective removal of arsenic from contaminated water using acetate functionalized zinc oxide nanomaterials," Environmental Progress \& Sustainable Energy, vol. 32, no. 4, pp. 1023-1029, 2013.

[27] A. Goswami, P. K. Raul, and M. K. Purkait, "Arsenic adsorption using copper (II) oxide nanoparticles," Chemical Engineering Research and Design, vol. 90, no. 9, pp. 13871396, 2012.

[28] R. Li, Q. Li, S. Gao, and J. K. Shang, "Exceptional arsenic adsorption performance of hydrous cerium oxide nanoparticles: part A. Adsorption capacity and mechanism," Chemical Engineering Journal, vol. 185-186, pp. 127-135, 2012.

[29] S. Mandal, M. K. Sahu, and R. K. Patel, “Adsorption studies of arsenic(III) removal from water by zirconium polyacrylamide hybrid material (ZrPACM-43)," Water Resources and Industry, vol. 4, pp. 51-67, 2013.

[30] Y. Li, S. Hu, and C. Jing, "Recent progress of arsenic adsorption on $\mathrm{TiO}_{2}$ in the presence of coexisting ions: a review," Journal of Environmental Sciences, vol. 49, pp. 74-85, 2016.

[31] G. Jegadeesan, S. R. Al-Abed, V. Sundaram, H. Choi, K. G. Scheckel, and D. D. Dionysiou, "Arsenic sorption on $\mathrm{TiO}_{2}$ nanoparticles: size and crystallinity effects," Water Research, vol. 44, no. 3, pp. 965-973, 2010.

[32] H. Y. Niu, J. M. Wang, Y. L. Shi, Y. Q. Cai, and F. S. Wei, "Adsorption behavior of arsenic onto protonated titanate nanotubes prepared via hydrothermal method," Microporous and Mesoporous Materials, vol. 122, no. 1-3, pp. 28-35, 2009.

[33] Z. Xu, Q. Li, S. Gao, and J. K. Shang, "As(III) removal by hydrous titanium dioxide prepared from one-step hydrolysis of aqueous $\mathrm{TiCl}_{4}$ solution," Water Research, vol. 44, no. 19, pp. 5713-5721, 2010.

[34] S. Bang, M. Patel, L. Lippincott, and X. Meng, "Removal of arsenic from groundwater by granular titanium dioxide adsorbent," Chemosphere, vol. 60, no. 3, pp. 389-397, 2005.

[35] C. Jing, X. Meng, E. Calvache, and G. Jiang, "Remediation of organic and inorganic arsenic contaminated groundwater using a nanocrystalline $\mathrm{TiO}_{2}$-based adsorbent," Environmental Pollution, vol. 157, no. 8-9, pp. 2514-2519, 2009.

[36] S. M. Miller and J. B. Zimmerman, "Novel, bio-based, photoactive arsenic sorbent: $\mathrm{TiO}_{2}$-impregnated chitosan bead," Water Research, vol. 44, no. 19, pp. 5722-5729, 2010.

[37] C. Y. Feng, K. C. khulbe, T. Matsuura, and A. F. Ismail, "Recent progresses in polymeric hollow fiber membrane preparation, characterization and applications," Separation and Purification Technology, vol. 111, pp. 43-71, 2013.

[38] D.-M. Wang and J.-Y. Lai, "Recent advances in preparation and morphology control of polymeric membranes formed by nonsolvent induced phase separation," Current Opinion in Chemical Engineering, vol. 2, no. 2, pp. 229-237, 2013.

[39] S. P. Deshmukh and K. Li, "Effect of ethanol composition in water coagulation bath on morphology of PVDF hollow fibre membranes," Journal of Membrane Science, vol. 150, no. 1, pp. 75-85, 1998.

[40] S. Fang, Y. Hu, L. Song, J. Zhan, and Q. He, "Mechanical properties, fire performance and thermal stability of magnesium hydroxide sulfate hydrate whiskers flame retardant silicone rubber," Journal of Materials Science, vol. 43, no. 3, pp. 1057-1062, 2008.

[41] Materials Data Book, Cambridge University Engineering Department, 2003, http://www-mdp.eng.cam.ac.uk/web/library/ enginfo/cueddatabooks/materials.pdf. 
[42] F. Liu, N. A. Hashim, Y. T. Liu, M. Abed, and K. Li, "Progress in the production and modification of PVDF membranes," Journal of Membrane Science, vol. 375, no. 1-2, pp. 1-27, 2011.

[43] T.-S. Chung, J.-J. Qin, and J. Gu, "Effect of shear rate within the spinneret on morphology, separation performance and mechanical properties of ultrafiltration polyethersulfone hollow fiber membranes," Chemical Engineering Science, vol. 55, no. 6, pp. 1077-1091, 2000.

[44] A. J. Reuvers and C. A. Smolders, "Formation of membranes by means of immersion precipitation," Journal of Membrane Science, vol. 34, no. 1, pp. 67-86, 1987.

[45] I. Katsoyiannis and A. Zouboulis, "Removal of arsenic from contaminated water sources by sorption onto iron-oxidecoated polymeric materials," Water Research, vol. 36, no. 20, pp. 5141-5155, 2002. 

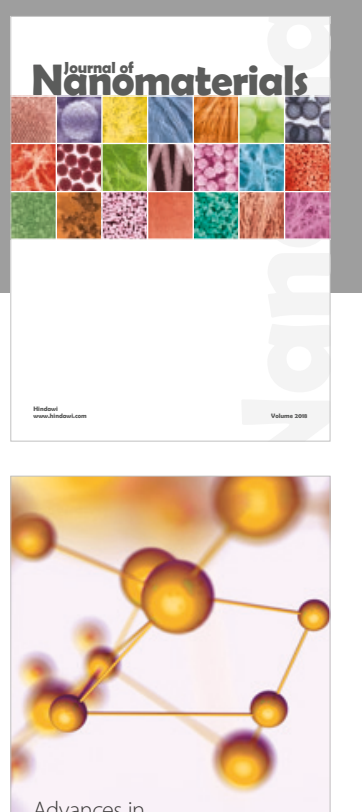

Physical Chemistry
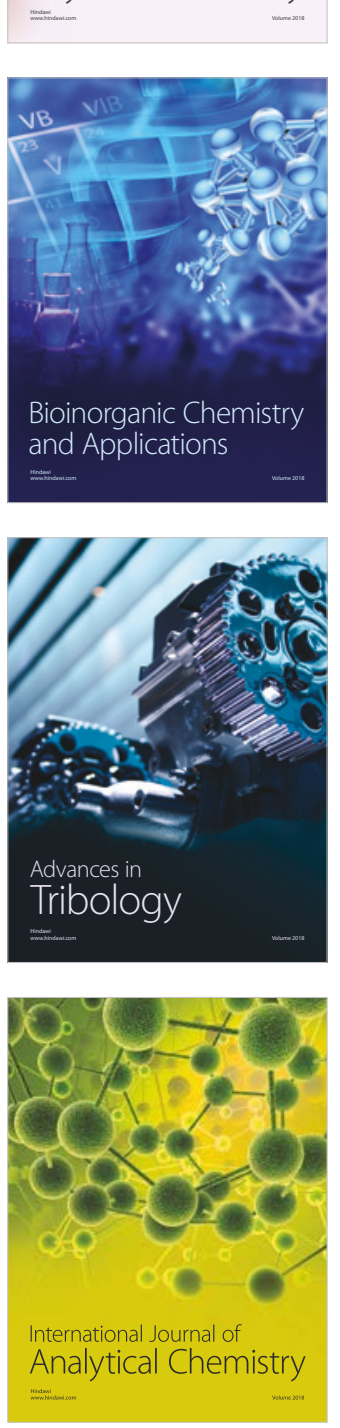

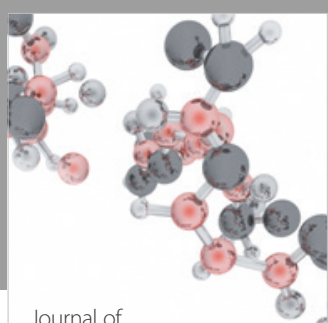

Analytical Methods

in Chemistry

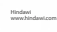

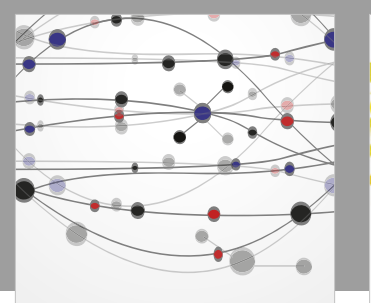

The Scientific World Journal

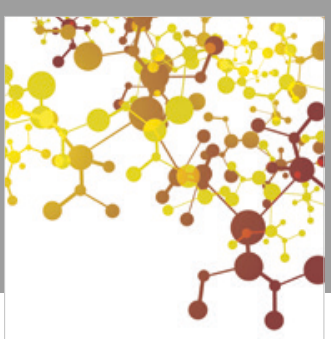

Journal of

Applied Chemistry
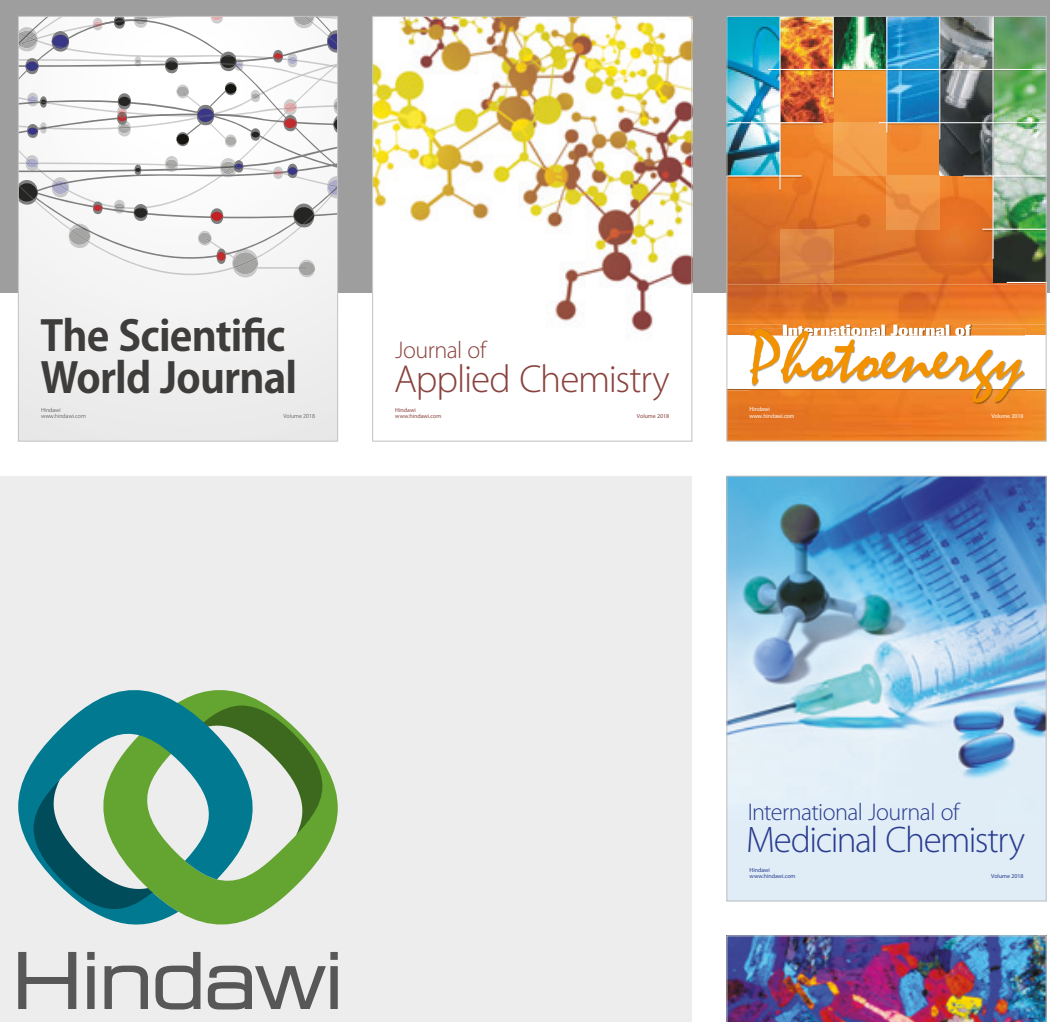

Submit your manuscripts at

www.hindawi.com
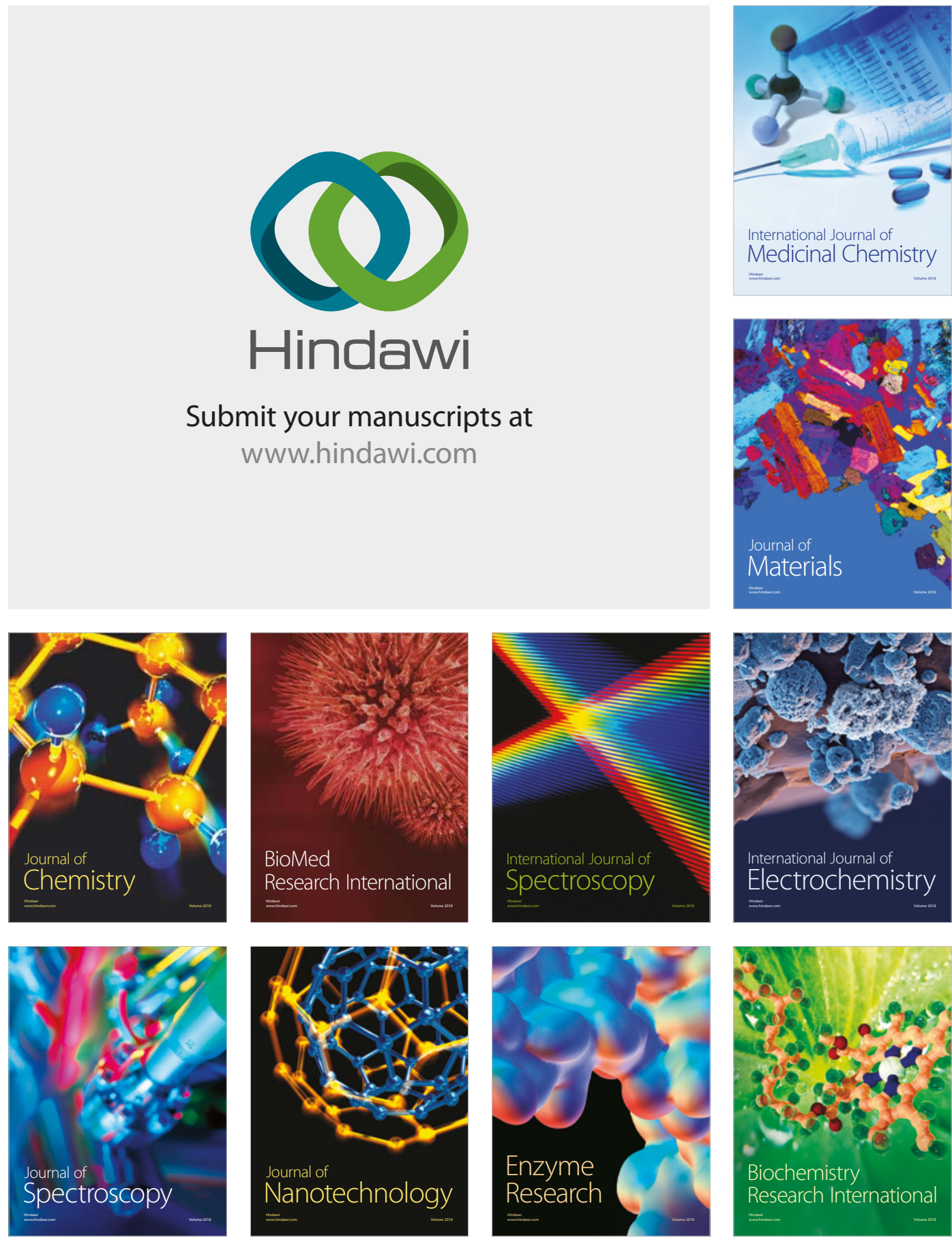
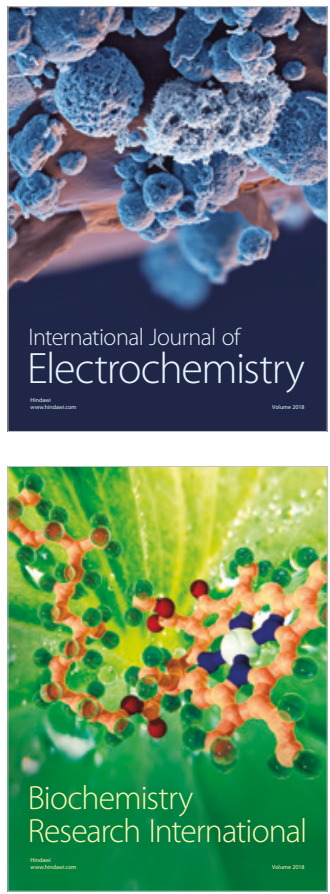